\title{
The Effect of Different Sugars on Water Kefir Grains
}

\author{
Tuncay Çevik ${ }^{1, a}$, Nilüfer Sena Aydoğdu1,b, Nilgün Özdemir ${ }^{2, c}$, Tuğba Kök Taş,d,* \\ ${ }^{1}$ Food Engineering Department, Faculty of Engineering, Süleyman Demirel University, 32260 Ísparta, Turkey \\ ${ }^{2}$ Food Engineering Department, Faculty of Engineering, Ondokuz Mayls University, 55139 Samsun, Turkey \\ *Corresponding author
}

A R T I C L E I N F O
"This study was presented as an oral
presentation at the 4th International
Anatolian Agriculture, Food,
Environment and Biology Congress
(Afyonkarahisar, TARGID 2019)

A B S T R A C T

Water kefir is a fermented probiotic beverage produced by fermentation of dried sugary fruits and sugar using water kefir grains. Sucrose is used as a sugar source in the traditional production of water kefir. The aim of this study is to determine the effects of grape molasses, honey and unrefined sugar on water kefir grains instead of sucrose. In the study, 4 groups were formed: grape molasses $(10 \mathrm{~g})$, honey $(10 \mathrm{~g})$, unrefined sugar $(10 \mathrm{~g})$ and refined sugar $(10 \mathrm{~g}) .2 \mathrm{~g}$ of water kefir grain and $500 \mathrm{~mL}$ of drinking water were used for each group. And each group samples were fermented for $25^{\circ} \mathrm{C} 48$

\section{Research Article}

hours. The study continued for 5 weeks. The $\mathrm{pH}$ values and the titratable acidity values of water kefir samples and the weight of water kefir grains were determinated once every two day, while microbiological analyzes (Lactobacillus spp., Lactococcus spp. and yeast contents) and ethanol

Received : 20/05/2019 Accepted : 05/08/2019 content of samples were determinate once every 15 days. In this study; it has been observed that the use of different sugars has no significant effect on the weights of the water kefir grains. In addition, it was determined that the Lactococcus spp. and yeast amounts in the water kefirs were higher in the samples produced by using honey and grape molasses. As a result, it was revealed that grape Keywords: Honey Grape molasses Probiotic beverage Vegetarian nutrition Water kefir molasses, honey and unrefined sugar could be used as fermentation substrate in production of water kefir. At the same time, water kefir can be shown as an alternative fermented product for vegan consumers with allergies to dairy products.

Türk Tarım - Gıda Bilim ve Teknoloji Dergisi 7(sp1): 40-45, 2019

\section{Su Kefir Daneleri Üzerinde Farklı Şekerlerin Etkisi}

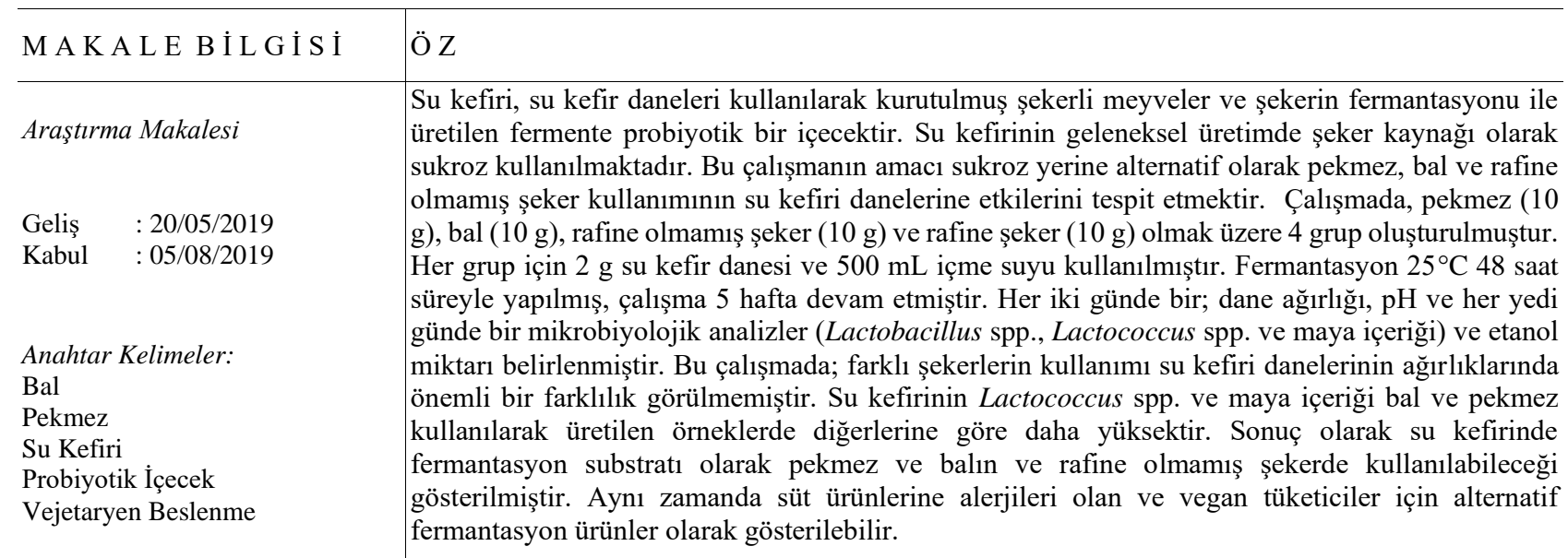




\section{Introduction}

In recent years; the interest in fermented food products has increased, due to its rich nutrient content and positive effects on health such as antioxidant, antimicrobial, anticancerogenic, antihyperlipidemic, antihyperglycemic, antimutagenic activities and probiotic property (Grishina et al., 2011; Bekar at al., 2011; Guzel-Seydim et al., 2014, Alsayadi et al., 2014; Koh et al., 2018). It is known that the source of these functional properties of fermented foods is the microorganism diversity in their microflora and the secondary metabolite products of them (Farnworth, 2005). The most striking of these functional-fermented foods is kefir.

Generally; kefir is known as a slightly carbonated, slightly acidic, viscous, refreshing, fermented milk product that has unique sensory properties due to a mixture of lactic acid, acetaldehyde, acetoin, ethanol, and other fermentation by-products. The natural production of them is carried out by the addition of kefir grains as starter cultures that start the fermentation of milk. The microflora of these kefir grains consist of a unique symbiotic association of different microorganisms, mainly lactic acid bacteria (LAB), yeasts and occasionally acetic acid bacteria, cohabiting in a natural polysaccharide matrix of semi-hard granules (Kök-Taş et al., 2013; Leite et al., 2013; Guzel-Seydim et al., 2014; Garofalo et al., 2015). In particular, the some probiotic LAB which found in high amounts $\left(\sim 10^{7-8} \log \mathrm{CFU} / \mathrm{mL}\right.$ or $\left.\mathrm{g}\right)$ such as Bifidobacter bifidum, B. longum, B. brevi in the kefir grain gain the probiotic property to the produced kefir with them (KökTaş, 2011; Magalhães et al., 2011).

It is known that milk is the most important nutrient for the growth of probiotic microorganisms (Oliveira 2009). Particularly, probiotic dairy products and the positive effect of them on human health are the important issues that do not lose the popularity of scientific studies (Bekar at al., 2011; Alsayadi et al., 2014). However, vegan, lactose intolerant and dairy-product allergic individuals been not able to consume dairy-products are deprived of these positive effects (Heenan et al., 2006; Schneedorf, 2012). Therefore; many researchers have conducted scientific studies on the usability of probiotic microorganisms in fermentation of different foods such as various fruit juices and cereal products (such as pomegranate juice, sourdough) (Blandio et al., 2003; Reichert 2008; Laureys et al., 2016). Also; the viability of probiotic microorganisms and producibility useful metabolite production are also investigated in non-fermented products such as sweets (Heenan et al., 2004). The best example for these alternative products is water kefir.

Water kefir is a non-dairy kefir prepared with a sugar solution fermented by water kefir grains, consisting of a consortium including mainly Kluyveromyces, Candida Pichia and Saccharomyces genera from yeasts (Saccharomyces florentinus, Candida valdiviana, Pichia fermentans, Zygosaccharomyces fermentati e.g.) and Lactobacillus, Lactococcus, Leuconostoc and Streptococcus genera from LAB (Lactobacillus hilgardii, Lactobacillus nagelii, Lactobacillus hordei Lactobacillus kefir e.g.). Also, in some water kefir grains, Acetobacter species (Acetobacter orientalis, A. tropicalis e.g.) were found. All these microorganisms are embedded in the kefir grains which had a gelling, water-soluble branched glucogalactan structure
(Rodrigues et al., 2005; Gulitz et al., 2011; Magalhães et al., 2011; Gabriela et al., 2011; Martinez-Torres et al., 2016). In addition, it is known that the sugary water solution, which is used as a raw material instead of milk in water kefir production, could be supplemented with the addition of dried or fresh fruit extracts (Martinez-Torres et al., 2016). Many scientific studies have shown that water kefir has a wide range of functional properties such as probiotic property (Bifidobacterium aquikefiri e.g.), hydrocolloid property, emulsifying and foam-forming activities (Laureys et al., 2016; Hermann et al., 2016). Therefore water kefir is considered to be a good alternative for those who cannot consume milk kefir.

The aim of this study is to reveal the usability of unrefined sugar, natural sweetener foods such as honey and grape molasses in water kefir production, and to determine the effect of honey, grape molasses and unrefined sugar on the change in the water kefir biomass which contained the microorganisms that are effective in the functional properties of the water kefir. Therefore, in this study, main microbiological and chemical properties and the changes in the biomasses of kefir grains of water kefir beverages produced using honey, grape molasses and unrefined sugar instead of refined sugar used as raw material in water kefir production were determined.

\section{Materials and Methods}

Water kefir grains were obtained from Danem Ltd. in the Lakes District Technopark at Suleyman Demirel University (Isparta, Turkey). Grape molasses (handmade) and honey (floral honey) were purchased from public bazaar (Isparta, Turkey) and Altıparmak Co. (Balparmak; İstanbul, Turkey), respectively. Unrefined sugar was obtained from İşmen Co (Irmak; İstanbul, Turkey).

Production of Water Kefir Beverages using Honey, Grape Molasses and Unrefined Sugar and Refined sugar

In the study, 4 group solutions (HS, MS, US, and CS respectively) prepared with the addition $2 \%$ each of honey, grape molasses, unrefined sugar, normal sugar for control sample added to the water. The solutions were activated with the water kefir grains $(0.4 \%)$, and fermented at $25^{\circ} \mathrm{C}$ for 48 hours. After fermentation, the water kefir grains (HWKG, MWKG, UWKG, and CWKG, respectively) were separated from the products produced for use in the production of kefir the next day. New-water kefir samples (HWK, MWK, UWK, and CWK, respectively) were produced using these solutions which re-prepared every other day during 5 weeks without interruption (Figure1). All assays were performed once a week for 5 weeks. The $\mathrm{pH}$ values in the samples were determined in line with the previously described method (Satir and Guzel-Seydim 2015).

\section{Microbiological Analysis}

The Lactobacillus spp. count was determined using a De Man, Rogosa, and Sharpe (MRS) medium (Merck, Darmstadt, Germany) after incubation at $37^{\circ} \mathrm{C}$ under $\mathrm{CO}_{2}$ (5\%) for 48 h. Lactococcus spp. and Streptococcus spp. counts were plated on M17 medium (Merck, Darmstadt, Germany) and incubated under $5 \% \mathrm{CO}_{2}$ at $37^{\circ} \mathrm{C}$ for $48 \mathrm{~h}$. 
Yeasts were grown on Potato Dextrose Agar (PDA) medium (Merck, Darmstadt, Germany) with $0.14 \%$ added lactic acid at $25^{\circ} \mathrm{C}$ for 5 days (Özdemir et al., 2015).

Determination of the Biomasses of Water Kefir Grains

The changes in the biomasses of water kefir grains in the water kefir beverages produced during 5 weeks without interruption were gravimetrically determined once a week for 5 weeks (Guzel-Seydim et al., 2011). Grains were aseptically separated using stainless steel sieves $(\varnothing 5 \mathrm{~cm})$ after fermentation. Grains were washed using sterile distilled water and transferred into autoclaved sterile aluminum weighing dishes containing sterilized paper towels to remove excess water. After the paper towels were removed, the water kefir grains were weighed using an analytical balance. Biomass was expressed as a percentage of the difference between final and initial grain weights to initial grain weights.

\section{Sensory Analysis}

Sensory evaluations were conducted using 15 panelists. The panelists were familiar with kefir properties and sensory testing. During early orientation sessions panelists were trained with kefir samples manufactured without any treatment. The panelists assigned a score to each sample based on a 7-point hedonic scale (1-7: strongly disliked and strongly liked, respectively) (Robinson et al. 2005; Ertekin and Guzel-Seydim 2010). The sensory data were measured using a sensory assessment form.

\section{Statistical Analysis}

All experiments were repeated three times, and the experimental results were expressed as mean \pm standard deviation of the mean, and they were, then, subjected to a one-way analysis of variance (ANOVA) using SPSS 18.0 (SPSS, 2010). A value of $\mathrm{P}<0.05$ was considered statistically significant.

\section{Results and Discussion}

\section{Microbial Enumeration Water Kefir Samples}

The 4 water kefir samples prepared with honey, grape molasses, unrefined sugar and refined sugar as control samples were analyzed. Analyzes were performed once a week for 5 weeks. According to the results (Figure 2.), it was determined that in the MKW samples, amounts of all the microorganisms groups were higher than them in the other samples. The microbial content of the HKW sample was second, followed by the UWK and the CWK samples, respectively. The low microbial content in the sample using the refined sugar shows that refined sugar adversely affects the microbial population of the water kefir.

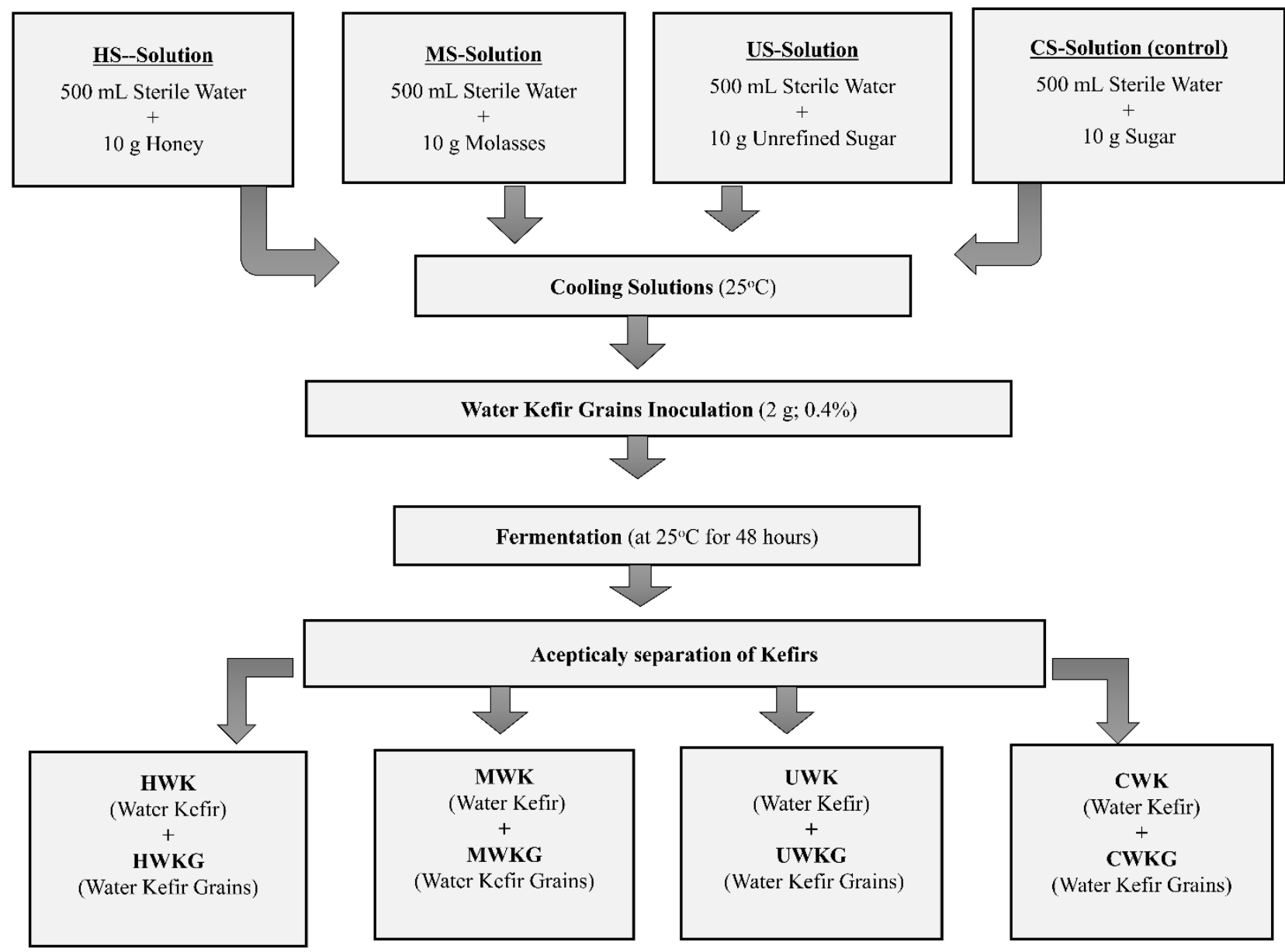

Figure 1 Flow chart for the production of water kefir samples.

(HWK and HWKG, MWK and MWKG, UWK and UWKG, CWK and CWKG water kefir samples and water kefir grains produced using honey, grape molasses, unrefined sugar and sugar, respectively.) 


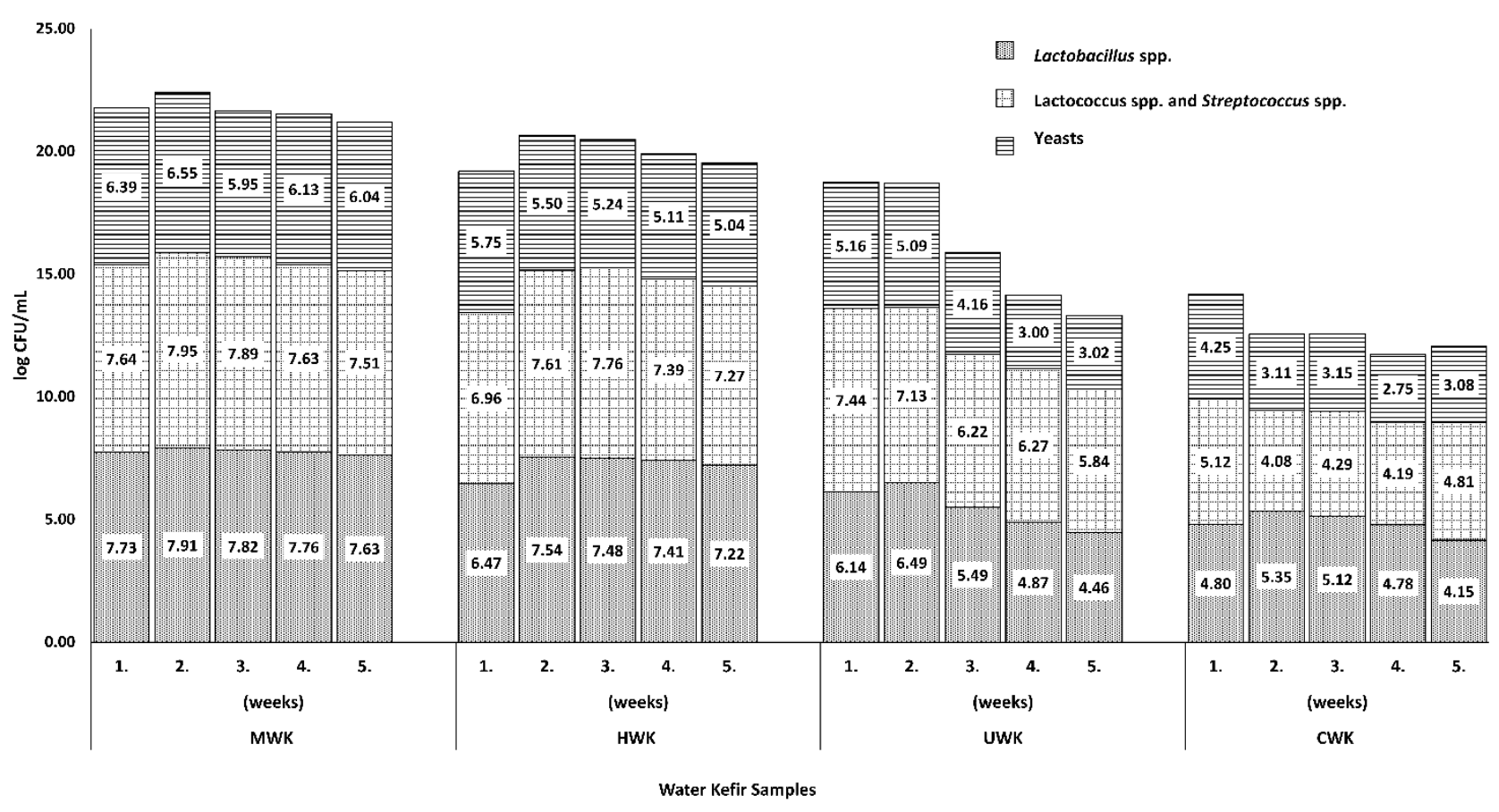

Figure 2 The microbial contents of water kefir samples.

(HWK, MWK, UWK and CWK water kefir samples produced using honey, grape molasses, unrefined sugar and refined sugar solutions, respectively.)

In the water kefir produced using same kefir grains during 5 weeks, the same condition was observed. However, a decrease/negative situation in the microflora of kefirs produced with non-refined sugar in time was also observed. In the production phase of refined sugar, it is thought that the processes applied, especially the refining process, and the added chemical compounds such as sulfur dioxide, blanket, hydrogen peroxide for whitening, affect the development of microorganisms (Aljohani et al., 2018; Babalouei and Tahghighi, 2018). The results were showed that yeasts Lactococcus spp.-Streptococcus spp. genera microorganisms were the most affected group of microorganisms $(\mathrm{P}<0.05)$. Sugar availability and sugar requirements of microorganisms are different (Choi et al., 2002). In the growth of yeast sugar is quite important and necessary (Choi et al., 2002; Koutinas, 2003; Laureys and De Vuyst 2014, Laureys et al., 2018). In present study, the presence of the sugars like fructose, sucrose except glucose in the grape molasses and the honey supports the results. In particular, the grape molasses contain sugar, such as saccharose, fructose, a small amount of maltose, and raffinose (Soukoulis and Tzia, 2018). Therefore, this situation positively affects the water kefir microflora. And grape molasses is thought to be suitable for microflora.

\section{$p H$ Values of Water Kefir Samples}

The results (Table 1) to $\mathrm{pH}$ analysis were shown that the highest acidity development of kefir samples was observed in HWK and MWK samples. However, this development was not found to be sufficient, especially in the CMK. The reason for this is that the microorganisms in the kefir microflora are considered to prefer nutrients with natural sugars because they are adversely affected by refined and unrefined sugars (Siva et al., 2009). Despite these results; The $\mathrm{pH}$ values (3.34-3.5) determined in the studies on water kefir (Laureys et al., 2017) and the $\mathrm{pH}$ values determined in the present study are in parallel.

\section{Changes in The Water Kefir Grain Biomass}

The changes in the grain biomasses of water kefir grains used as a natural starter culture to make water kefir were examined during 5 weeks (Table 2). Generally, it could have observed the significant differences between the samples in the same weeks until third week $(\mathrm{P}>0.05)$. But, after third week, it was found that the water kefir grain biomass of the MWK and HWK samples were much than the others $(\mathrm{P}<0.05)$. On the other hand, it was determined that the increases in the water kefir grain biomass of the MWK and HWK samples and the decreases in them of the other samples were significant during 5 weeks $(\mathrm{P}<0.05)$.

Table 1 Changes in the $\mathrm{pH}$ values of water kefirs during 5 weeks.

\begin{tabular}{l|ccccc}
\hline \multicolumn{1}{c|}{ Samples $^{*}$} & 1. week & 2. week & 3. week & 4. week & 5. week \\
\hline MWK & $4.06 \pm 0.06^{\mathrm{aC} * *}$ & $4.08 \pm 0.11^{\mathrm{aC}}$ & $3.95 \pm 0.41^{\mathrm{abC}}$ & $3.89 \pm 0.33^{\mathrm{abC}}$ & $3.94 \pm 0.05^{\mathrm{abC}}$ \\
HWK & $3.56 \pm 0.12^{\mathrm{cD}}$ & $3.67 \pm 0.09^{\mathrm{bD}}$ & $3.75 \pm 0.21^{\mathrm{aC}}$ & $3.56 \pm 0.16^{\mathrm{cC}}$ & $3.61 \pm 0.24^{\mathrm{bC}}$ \\
UWK & $4.52 \pm 0.03^{\mathrm{dB}}$ & $4.63 \pm 0.12^{\mathrm{cB}}$ & $4.72 \pm 0.06^{\mathrm{bB}}$ & $4.89 \pm 0.22^{\mathrm{aB}}$ & $4.83 \pm 0.13^{\mathrm{aB}}$ \\
CWK & $5.62 \pm 0.14^{\mathrm{aA}}$ & $5.58 \pm 0.05^{\mathrm{aA}}$ & $5.43 \pm 0.16^{\mathrm{bA}}$ & $5.41 \pm 0.08^{\mathrm{bA}}$ & $5.46 \pm 0.09^{\mathrm{abA}}$ \\
\hline
\end{tabular}

${ }^{*} \mathrm{HWK}$, MWK, UWK and CWK water kefir samples produced using honey, grape molasses, unrefined sugar and refined sugar solutions, respectively. ${ }^{* *} \mathrm{~A}-\mathrm{D}$ Different lowercase letters indicate significant differences between the samples in the same week $(\mathrm{P}<0.05)$. a-c Different uppercase letters indicate significant differences between weeks during 5 weeks $(\mathrm{P}<0.05)$. 
Table 2 Changes in the water kefir grain biomasses during 5 weeks (g)

\begin{tabular}{l|lllll}
\hline \multicolumn{1}{c|}{ Samples $^{*}$} & \multicolumn{1}{c}{ 1. week } & \multicolumn{1}{c}{ 2. week } & 3. week & 4. week & 5. week \\
\hline MWK & $2.01 \pm 0.05^{\mathrm{cA} \mathrm{A}^{* *}}$ & $2.09 \pm 0.17^{\mathrm{bA}}$ & $2.11 \pm 0.03^{\mathrm{bA}}$ & $2.13 \pm 0.06^{\mathrm{bA}}$ & $2.19 \pm 0.18^{\mathrm{aA}}$ \\
HWK & $2.01 \pm 0.19^{\mathrm{cA}}$ & $2.07 \pm 0.13^{\mathrm{bAB}}$ & $2.09 \pm 0.09^{\mathrm{bA}}$ & $2.11 \pm 0.34^{\mathrm{bA}}$ & $2.15 \pm 0.08^{\mathrm{aA}}$ \\
UWK & $2.05 \pm 0.10^{\mathrm{aA}}$ & $2.05 \pm 0.03^{\mathrm{aB}}$ & $2.03 \pm 0.13^{\mathrm{aB}}$ & $2.06 \pm 0.21^{\mathrm{aB}}$ & $1.92 \pm 0.14^{\mathrm{bB}}$ \\
CWK & $2.06 \pm 0.11^{\mathrm{abA}}$ & $2.09 \pm 0.05^{\mathrm{aA}}$ & $2.08 \pm 0.10^{\mathrm{aA}}$ & $2.04 \pm 0.40^{\mathrm{abB}}$ & $1.97 \pm 0.02^{\mathrm{cdB}}$ \\
\hline
\end{tabular}

${ }^{*} \mathrm{HWK}, \mathrm{MWK}$, UWK and CWK water kefir samples produced using honey, grape molasses, unrefined sugar and refined sugar solutions, respectively. ${ }^{* *}$ A-B Different lowercase letters indicate significant differences between the samples in the same week $(\mathrm{P}<0.05)$. a-c Different uppercase letters indicate significant differences between weeks during 5 weeks $(\mathrm{P}<0.05)$

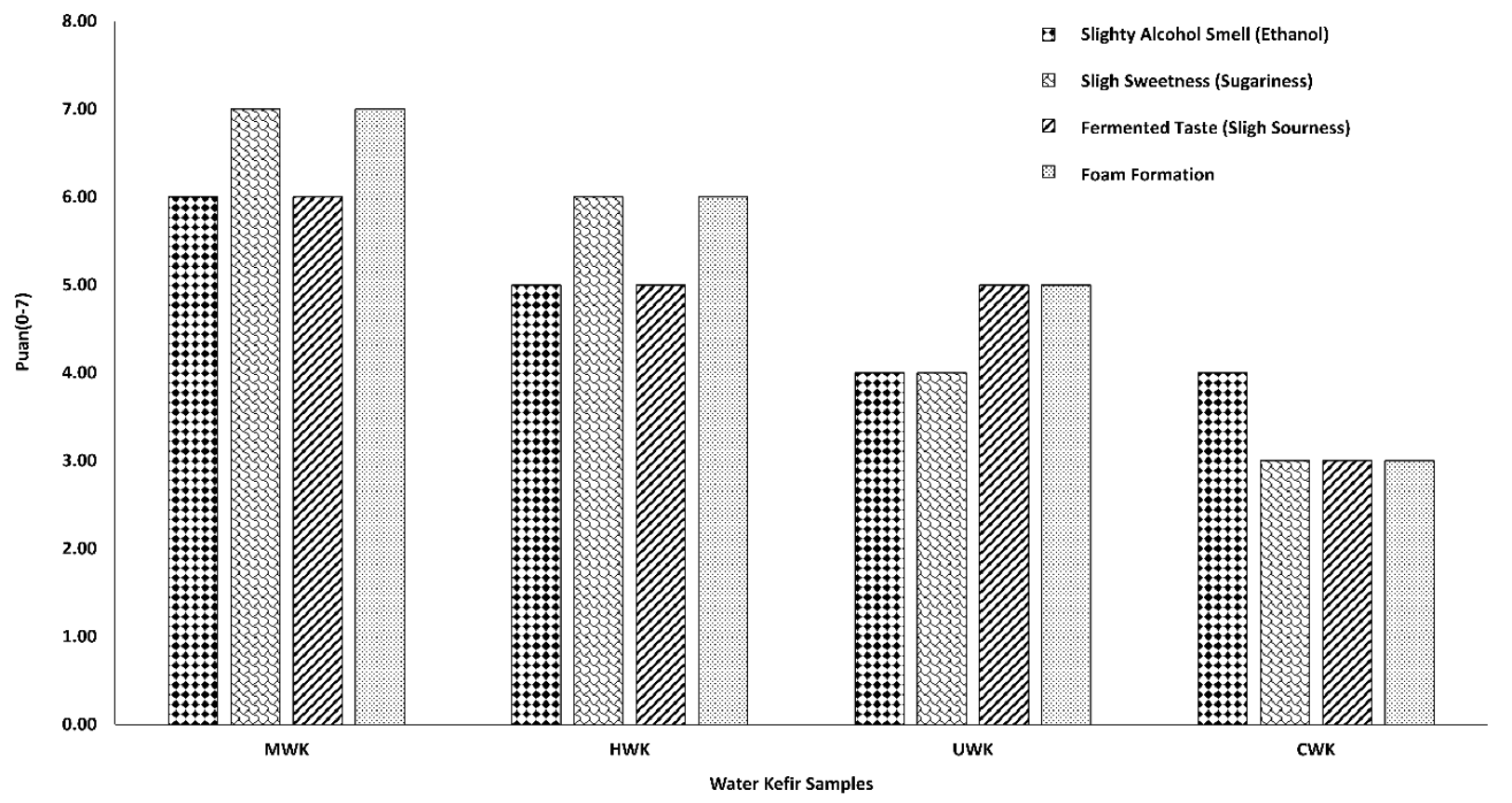

Figure 3 The hedonic tests evaluation of water kefir samples at end day of 5. week

(HWK, MWK, UWK and CWK water kefir samples produced using honey, grape molasses, unrefined sugar and refined sugar solutions, respectively)

Basically, the microorganisms that are capable of producing exopolysaccharide (EPS) are responsible for the change in the grains biomass. And, these microorganisms can use different sugars like sucrose, fructose except glucose in the EPS production (Jeong et al., 2017). The use of grape molasses and honey containing sugars, such as fructose and sucrose (Karaman et al., 2017), had little effect on EPS production. In additional, in a study (Laureys and De Vuyst, 2014), it was observed that the biomasses of water kefir grains increased only during 48 hours, then remained stable. It is consider that in the present study, the 48-hour fermentation period limited the detection of this condition.

\section{Sensory Properties of Water Kefir Samples}

When the sensory properties of kefir were examined (Figure 3); Similar results were obtained from other analyzes. Since microorganism metabolites are effective in the formation of aroma components (Laureys and De Vuyst, 2014), similarity can be established between the microbial content and the sensory properties of water kefirs. In particular, the ethanol and the carbon dioxide produced from the yeast effect are effective on the foam formation and slightly alcohol smell properties (Hermann et al., 2016; Laureys et al, 2017). Since glucose is used faster than other sugars, these properties are expected to be high in products with high glucose content. However, although the glucose contents of UWK and CWK samples are high, that the ethanol and the carbon dioxide produced during the long fermentation process turn into different compounds and the microflora cannot show sufficient activity due to the additives, adversely affects the sensory properties of the water kefir samples. Therefore; the preferred sensory balance was observed in MWK and HMK samples. The higher score of the HMK sample was observed especially in slight sweetness. This is due to the fact that honey has a more pleasing taste than grape molasses.

In the present study, it was revealed that the use honey and grape molasses solutions in the water kefir beverages production honey and grape molasses solutions is very convenient. While the grape molasses positively effects the microflora of the water kefir grains, the honey positively effects both the microflora of the water kefir grains and sensory properties. In additional, the use of different sugarcontaining solutions in water kefir production does not significantly affect the biomass.

The water kefirs produced with the honey and grape molasses solutions are a good alternative beverage instead of probiotic dairy products. Beside, these production that using the honey and the grape molasses instead of unrefined sugar and refined sugar is considered increasing the positive effects on human health of the water kefirs. 


\section{Acknowledgments}

This work was supported by the Danem Co. (Isparta, Turkey) provided natural water kefir grains. The authors express their gratitude to the Danem Co. and declare that there is no conflict of interest to disclose.

\section{References}

Aljohani H, Ahmed Y, El-Shafey O, El-Shafey S, Fouad R, Shoueir, K. 2018. Decolorization of turbid sugar juice from sugar factory using waste powdered carbon. Appl. Water Sci., 8: 48. doi.org/10.1007/s13201-018-0681-2.

Babalouei F, Tahghighi A. 2018. Evaluation of remaining blankit in refined Iranian sugar products through ion exchange resins. Int Food Res J., 25: 4

Bekar O, Y1lmaz Y, Gulten M, 2011. Kefir Improves the Efficacy and Tolerability of Triple Therapy in Eradicating Helicobacter pylori. J Med Food., 14: 344-347.

Blandino A, Al-Aseeri ME, Pandiella, SS, Cantero D, Webb C. 2003. Cereal-based fermented foods and beverages. Food Res. Int. 36: 527-543.

Ertekin B, Guzel-Seydim ZB. 2010. Effect of fat replacers on kefir quality. J. Sci. Food Agric. 90: 543-548. doi.org/10.1002/jsfa.3855.

Farnworth ER. 2005. Kefir - a complex probiotic. Food Science and Technology Bulletin: doi 10.1616/1476-2137.13938.

Fiorda FA. 2016. Development of new potentialy probiotic honey beverage fermented by kefir grains= functional properties, molecular microbiological characteristics and technological aspects. Funct Foods, 2: 1-17.

Garofalo C, Osimani A, Milanović V, Aquilanti L, De Filippis F, Stellato G, Di Mauro S, Turchetti B, Buzzini P, Ercolini D, Clementi F. 2015. Bacteria and yeast microbiota in milk kefir grains from different Italian regions. Food Microbiol., 49: 123-133. doi.org/10.1016/j.fm.2015.01.017.

Grishina A, Kulikova I, Alieva L, Dodsonb A, Rowlandb I, Jin J. 2011. Antigenotoxic Effect of Kefir and Ayran Supernatants on Fecal Water-Induced DNA Damage in Human Colon Cells. Nutr Cancer., 63: 73-79. doi: 10.1080/01635581.2010.516873.

Guzel-Seydim Z, Kök-Taş T, Ertekin B, Seydim, AC. 2011. Effect of fat replacers on biomass increase in kefir grains. J Dairy Sci., 94: 1239- 42. doi.org/10.3168/jds.2010-3349.

Heenan CN, Adams MC, Hosken RW, Fleet GH. 2004. Survival and sensory acceptability of probiotic microorganisms in a nonfermented frozen vegetarian dessert. LWT Food Sci. Technol., 37: 461-466. doi.org/10.1016/j.lwt.2003.11.001.

Hermann M, Kronseder K, Sorgend J, Ua-Arak T, Vogel R F. 2016. Functional properties of water kefiran and its use as a hydrocolloid in baking. Eur. Food Res. Technol., 242: $337-$ 344. doi 10.1007/s00217-015-2543-6.

Jeong D, Kim DH, Kang IB, Kim H, Song KY, Kim HS, Seo KH. 2017. Characterization and antibacterial activity of a novel exopolysaccharide produced by Lactobacillus kefiranofaciens DN1 isolated from kefir. Food Control, 78: 436-442. doi.org/10.1016/j.foodcont.2017.02.033.
Karaman S, Yilmaz MT, Ozturk G, Yuksel F, Toker ÖS, Dogan M. 2017. Characterization of Grape Molasses/Sesame Paste/Honey Blends: Multiple Response Optimization of Some Physicochemical, Bioactive, Viscoelastic and Sensory Properties. J. Food Process Eng., 40: e12406. doi.org/10.1111/jfpe.12406.

Koh WY, Utra U, Ahmad R, Rather I A, Park YH. 2018. Evaluation of probiotic potential and anti-hyperglycemic properties of a novel Lactobacillus strain isolated from water kefir grains. Food Sci. Biotechnol., 27: 1369-1376. doi.org/10.1007/s10068-018-0360-y.

Kök-Taş T, Ekinci, FY, Güzel-Seydim, ZB. 2011. Identification of microbial flora in kefir grains produced inTurkey using PCR. Int. J. Dairy Technol., 64: 1-6. doi.org/10.1111/j.14710307.2011.00733.x.

Kök-Taş,T, Seydim AC, Özer, B, Guzel-Seydim, ZB. 2013. Effects of different fermentation parameters on quality characteristics of kefir. J. Dairy Sci., 96: 780-789. doi.org/10.3168/jds.2012-5753.

Koutinas AA. 2003. New Trends in Kefir Yeast Technology. In new horizons in biotechnology Springer, Dordrecht, p. 297309. doi.org/10.1007/978-94-017-0203-4_27.

Laureys D, De Vuyst, L. 2014. Microbial species diversity, community dynamics, and metabolite kinetics of water kefir fermentation. Appl. Environ. Microbiol., 80: 2564-2572. doi:10.1128/AEM.03978-13.

Laureys D, De Vuyst, L. 2017. The water kefir grain inoculum determines the characteristics of the resulting water kefir fermentation process. J. Appl. Microbiol., 122: 719-732. doi.org/10.1111/jam.13370.

Laureys D, Aerts M, Vandamme P, De Vuyst L. 2018. Oxygen and diverse nutrients influence the water kefir fermentation process. Food Microbiol., 73: 351-361. doi.org/10.1016/j.fm.2018.02.007

Laureys D, Cnockaert M, De Vuyst L, Vandamme P. 2016. Bifidobacterium aquikefiri sp. Nov., isolated from water kefir. Int. J. Syst. Evol. Microbiol., 66: 1281-1286. doi: 10.1099/ijsem.0.000877.

Oliveira MND. 2009. Tecnologia de produtos lácteos funcionais. São Paulo: Atheneu.

Randazzo W, Corona O, Guarcello R, Francesca N, Germana, MA, Erten H, Moschetti G, Settanni L. 2016. Development of new non-dairy beverages from Mediterranean fruit juices fermented with water kefir microorganisms. Food Microbiol., 54: 40-51. doi.org/10.1016/j.fm.2015.10.018.

Reichert N. 2008. Cargill beverage concepts will address consumer demands for health, taste and texture at IFT 2008.

Satir G, Guzel-Seydim ZB. 2015. Influence of kefir fermentation on the bioactive substances of different breed goat milks. LWT Food Sci. Technol., 63: 852-858. doi.org/10.1016/j.lwt.2015.04.057

Schneedorf JM. 2012. Kefir D'Aqua and its probiotic properties. In Probiotic in Animals. InTech, Open Science Open Minds. doi.org/10.5772/50053.

Silva KR, Rodrigues SA, Xavier Filho L, Lima ÁS. 2009. Antimicrobial activity of broth fermented with kefir grains. Appl Biochem Biotechnol, 152: 316-325. doi 10.1007/s12010-008-8303-3.

Soukoulis C, Tzia C. 2018. Grape, raisin and sugarcane molasses as potential partial sucrose substitutes in chocolate ice cream: A feasibility study. Int. Dairy J., 76: 18-29. doi.org/10.1016/j.idairyj.2017.08.004 